\title{
Detection of Sirtuin-1 protein expression in peripheral blood leukocytes in dogs
}

\author{
Kuniko YOSHIMURA ${ }^{1)}$, Aya MATSUU ${ }^{2)}$, Kai SASAKI') and Yasuyuki MOMOI')* \\ 1)Laboratory of Veterinary Diagnostic Imaging, Joint Faculty of Veterinary Medicine, Kagoshima University, \\ 1-21-24 Korimoto, Kagoshima 890-0065, Japan \\ ${ }^{2)}$ Transboundary Animal Diseases Research Center, Joint Faculty of Veterinary Medicine, Kagoshima University,
} 1-21-24 Korimoto, Kagoshima 890-0065, Japan

J. Vet. Med. Sci.

80(7): 1068-1076, 2018

doi: 10.1292/jvms.17-0499

Received: 6 September 2017

Accepted: 1 May 2018

Published online in J-STAGE:

11 May 2018
ABSTRACT. Sirtuin-1 (SIRT1) is a nicotinamide adenine dinucleotide (NAD ${ }^{+}$)-dependent histone deacetylase with a large number of protein substrates. It has attracted a lot of attention in association with extending lifespan. The objective of this study was to enable the evaluation of SIRT1 expression in peripheral blood mononuclear cells (PBMCs) from dogs by flow cytometry. Three transcript variants were amplified from PBMCs by reverse transcription PCR and the nucleotide sequences were analyzed. On the basis of deduced amino acid sequence, a monoclonal antibody against human SIRT1, 1F3, was selected to detect canine SIRT1. Canine SIRT1 in peripheral blood mononuclear cells was successfully detected by western blotting using this antibody. Intracellular canine SIRT1 was also detected in permeabilized 293T cells transfected with a canine SIRT1 expression plasmid by flow cytometry using this antibody. SIRT1 was detected in all leukocyte subsets including lymphocytes, granulocytes and monocytes. The expression level was markedly different among individual dogs. These results indicated that the method applied in this study is useful for evaluating canine SIRT1 levels in PBMCs from dogs.

KEY WORDS: dog, flow cytometry, sirtuin-1

Previous studies have characterized Sir2 protein as a pro-longevity factor for replicative lifespan in yeast [15, 20, 26, 46, 53]. Sir2 orthologs also extended lifespan in other organism species including Caenorhabditis elegans and flies [43, 50]. Because it has been suggested that the beneficial effects of caloric restriction on lifespan are mediated by Sir2 orthologs in higher eukaryotes [4, $7,8,44]$, sirtuins received significant public interest. Sirtuins are a family of highly conserved nicotinamide adenine dinucleotide $\left(\mathrm{NAD}^{+}\right)$-dependent protein deacylases found in eukaryotes. In humans, there are seven sirtuin homologs (SIRT1-7). All sirtuins require $\mathrm{NAD}^{+}$as a cofactor, making them prone to regulation by fluctuations in $\mathrm{NAD}+$ conditions, thus linking them to cellular metabolism in response to nutritional and environmental perturbations such as caloric restriction. Of all the sirtuins, SIRT1 has received the most attention in relation to longevity. It deacetylates key histone residues involved in transcription regulation, and multiple non-histone proteins including p53, FOXO1/3, PGC-1 $\alpha$ and NF- $\kappa \mathrm{B}[11,37,51]$. By targeting these proteins, SIRT1 is able to regulate numerous vital signaling pathways, including DNA repair, apoptosis, muscle and fat differentiation, neurogenesis, mitochondrial biogenesis, hormone secretion, cell stress responses and circadian rhythms [3, 37, 42]. In general, SIRT1 activation triggers nuclear transcription programs that enhance metabolic efficiency and up-regulate mitochondrial oxidative metabolism accompanying resistance to oxidative stress $[13,16]$.

SIRT1 is expressed in systemic organs and localizes primarily in the nucleus [37]. SIRT1 is also detected in the cytoplasm of granulocytes and monocytes [47]. Though its enzymatic activity has been measured to evaluate its potential inhibitors and activators using cultured cells or recombinant SIRT1 [14] with respect to longevity, it is usually difficult to evaluate its activity in tissue samples obtained from patients. Thus SIRT1 expression was evaluated by measuring mRNA transcription, tissue SIRT1 protein expression or plasma SIRT1 concentration in association with nutritional conditions or diseases [10, 21, 23, 24, 29, 35, 36, $38,49]$. Not only SIRT1 activation but also increasing SIRT1 expression is related to lifespan extension in experimental condition [2]. Compounds that increase SIRT1 expression have been intently screened and reported [41].

To our knowledge, there are few published studies measuring SIRT1 level in companion animals [17, 18, 30, 31]. In dogs, there are two reports: one is in association with the p53 mutations status in a dog with multiple tumors [31], and the other evaluated SIRT1 gene expression in a cell line in relation to coronavirus infection [30]. The reason for the low number of studies is, at least in part by, the lack of antibodies to detect canine SIRT1.

The aim of this study is to determine the nucleotide sequence of canine SIRT1 mRNA and make SIRT1 protein detection

*Correspondence to: Momoi, Y.: k5241972@kadai.jp

O2018 The Japanese Society of Veterinary Science

This is an open-access article distributed under the terms of the Creative Commons Attribution Non-Commercial No Derivatives (by-nc-nd) License. (CC-BY-NC-ND 4.0: https://creativecommons.org/licenses/by-nc-nd/4.0/) 
Table 1. Oligo nucleotide primers used in this study

\begin{tabular}{lllcl}
\hline & Primer name & Nucleotide sequence (5'-3') & Position $^{\text {a) }}$ & Remarks \\
\hline For 1st reverse- & Sense_1 & ggaggagggccagagaggcagtt & $71-93$ & For 5' fragment amplification \\
trasnscription PCR & Reverse_1 & ggtggaacaattcctgtacct & $2371-2351$ & \\
\cline { 2 - 5 } & Sense_2 & agactgtgaagctgtacgag & $1220-1239$ & For 3' fragment amplification \\
& Reverse_2 & cctgaaactcttagcaccaag & $2981-2961$ & \\
\hline For nested PCR & Sense_3 & agttggaagatggcggacga & $90-109$ & For 5' fragment amplification \\
& Reverse_3 & ggcatattcaccacctaacc & $1580-1561$ & \\
\cline { 2 - 5 } & Sense_2 & agactgtgaagctgtacgag & $1220-1239$ & For 3' fragment amplification \\
& Reverse_1 & ggtggaacaattcctgtacct & $2371-2351$ & \\
\hline For 5'-RACE & RT-primer & (P)-aaacattgcttgagg & $977-963$ & Phosphorylated at 5' end for RACE \\
\cline { 2 - 5 } & S1-primer & gtttcttgtggaatacctgact & $882-903$ & For 1st PCR \\
& A1-primer & ggaggaattgtttctggtagt & $721-701$ & \\
\cline { 2 - 5 } & S2-primer & gcaatagacttcccagacct & $936-955$ & For 2nd PCR \\
& A2-primer & ggatctgtgccaatcatgag & $679-660$ & \\
\hline
\end{tabular}

a) Nucleotide data from predicetd canine SIRT1 cDNA sequence (GeneBank accession No. XM_546130.5).

possible in lymphocytes, which are easily available in veterinary clinical settings. Flow cytometry was applied to clinical cases to obtain basic information on SIRT1 expression in canine lymphocytes.

\section{MATERIALS AND METHODS}

\section{Animals and blood samples}

Dogs were client owned or protection dogs brought to the Kagoshima University Veterinary Teaching Hospital for veterinary care. Residues of heparinized blood samples applied for biochemical tests were used in this study. Information including the patient's signalment, body condition score (5 points scale), diagnosis and undergoing treatment was obtained from the veterinary medical record or from the veterinarians in charge.

\section{Determination of canine SIRT1 mRNA nucleotide sequence}

Total RNA was extracted from an EDTA-K2-treated blood sample from client owned dogs using a PureLink RNA Mini Kit (ThermoFisher Scientific, Waltham, MA, U.S.A.). Reverse transcription polymerase chain reaction (PCR) was performed using Primescript One Step RT-PCR kit (Takara, Kusatsu, Japan). In a preliminary experiment, we could not amplify cDNA fragments encompassing the whole predicted canine SIRT1 coding region (GenBank Accession No. XM_546130.4). Thus, primer pairs were designed to amplify two overlapping DNA fragments that cover the whole SIRT1 coding region by nested and semi-nested PCR. In the first PCR, 5'-end and 3'-end DNA fragments were amplified by One-Step RT-PCR using the Sense_1-Reverse_1 and Sense_2-Reverse_2 primer pairs, respectively (Table 1). PCR conditions were $94^{\circ} \mathrm{C}$ for $2 \mathrm{~min}$, followed by 30 cycles of $94^{\circ} \mathrm{C}$ for $30 \mathrm{sec}, 55^{\circ} \mathrm{C}$ for $30 \mathrm{sec}$ and $72^{\circ} \mathrm{C}$ for $3 \mathrm{~min}$. Then RT-PCR products were used as templates, nested and semi-nested PCRs were conducted by GoTaq ${ }^{\circledR}$ Hot Start Colorless Master Mix (Promega, Madison, WI, U.S.A.), to amplify 5' and 3' cDNA fragments using the Sense_3-Reverse_3 and Sense_2-Reverse_1 primer pairs (Table 1). The PCR conditions were the same as the first PCR. The second set of PCR products were electrophoresed in $2 \%$ agarose. DNA fragments were extracted from the gel and purified using High Pure PCR Product Purification Kit (Roche Diagnostics, Mannheim, Germany). The nucleotide sequence was determined by the dye terminator method at a commercial laboratory, Fasmac (Atsugi, Japan). We also investigated canine SIRT1 transcript variants by $5^{\prime}$-terminal inverse PCR amplification. Total RNA was extracted as mentioned above from blood samples obtained from a client owned Labrador Retriever. The 5'-end of canine SIRT1 cDNA was amplified using a 5'-Full RACE Core Kit (Takara) according to the manufacturer's instructions. The nucleotide sequence of the 5'-phosphorylated primer for reverse transcription (RT-primer) is shown in Table 1. Inverse nested PCRs were performed using GoTaq ${ }^{\circledR}$ Hot Start Colorless Master Mix. The nucleotide sequences of the primers for the first (S1-A1 primers) and nested PCR (S2-A2 primers) are shown in Table 1. The PCR conditions for the first and second PCRs were $94^{\circ} \mathrm{C}$ for $2 \mathrm{~min}$, followed by 30 cycles of $94^{\circ} \mathrm{C}$ for $30 \mathrm{sec}, 55^{\circ} \mathrm{C}$ for $30 \mathrm{sec}$ and $72^{\circ} \mathrm{C}$ for $3 \mathrm{~min}$. The amplified PCR products were electrophoresed and purified as mentioned above, to determine the nucleotide sequences.

\section{Western blot analysis of canine SIRT1 protein}

We conducted to detect canine endogenous SIRT1 protein levels in PBMCs by western blotting. Heparinized blood sample from two client owned dogs was used for the analysis. The samples were overlaid on Lympholyte-H specific gravity 1.077 (Cedarlane, Burlington, Ontario, Canada) and centrifuged at $900 \times \mathrm{g}$ for $30 \mathrm{~min}$. PBMCs were collected and washed in phosphate-buffered saline (PBS). Human embryonic kidney cells 293 (HEK293) [12] and Madin-Darby canine kidney cells (MDCK) [28] were also used for western blotting as a source of human and canine SIRT1 protein. Cultured cells were resuspended in PBS and an equal 

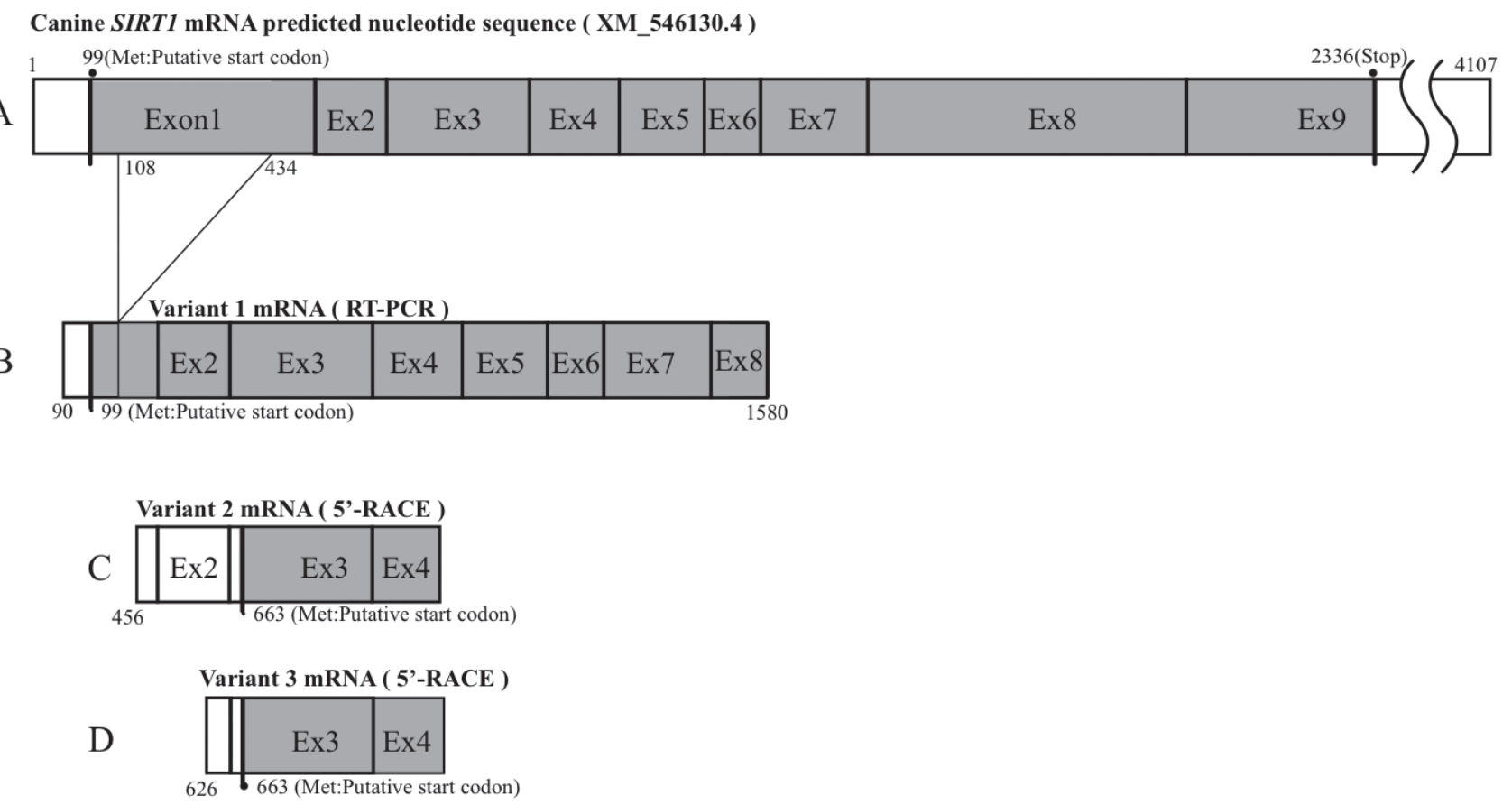

Fig. 1. Schematic view of the structure of the canine SIRT1 mRNA variants. A: Predicted canine SIRT1 mRNA structure (XM_546130.4). B: Putative gene structure of a canine SIRT1 mRNA transcript variant (variant 1) obtained by RT-PCR using RNA from canine PBMC. C, D: Putative 5' terminal mRNA structure obtained by 5' RACE using RNA from PBMC. The translation start codon was predicted using the ATGpr program.

volume of 2x sample buffer [0.125 M Tris-HCl, pH 6.8, 10\% (v/v) 2-mercaptoethanol, 4\% sodium dodecyl sulfate (SDS), 10\% sucrose, $0.01 \%$ Bromophenol blue], and incubated at $95^{\circ} \mathrm{C}$ for $3 \mathrm{~min}$. Samples were stored at $-20^{\circ} \mathrm{C}$ until use. Twenty microliters of each sample at the concentration of $2.5-5 \mathrm{mg} / \mathrm{m} l$ protein concentration (Bradford protein assay kit, Takara) were loaded on $8 \%$ polyacrylamide gels and electrophoresed. Samples were transferred to nitrocellulose membranes (GE Nitrocellulose ${ }^{\mathrm{TM}}$ Pure Unsupported Nitrocellulose Membranes, GVS Filter Technology, Emilia-Romagna, Italy) using Trans blot SD Semi-Dry Transfer Cell (Bio-rad, Hercules, CA, U.S.A.). The membranes were washed with Tris-buffered saline with $0.1 \%$ Tween (TBS-T: $0.05 \mathrm{M}$ Tris, $0.138 \mathrm{M} \mathrm{NaCl}, 0.0027 \mathrm{M} \mathrm{KCl}$ and $0.1 \%$ Tween20), and then incubated in $1 \mathrm{x}$ TBS-T supplemented with 5\% (w/v) Nonfat Dry milk (Cell Signaling Technology, Danvers, MA, U.S.A.). The membranes were washed with $1 \mathrm{x}$ TBS-T, and then incubated with the anti-human SIRT1 monoclonal antibody, 1F3 (Cell Signaling Technology), diluted in $1 \mathrm{x}$ TBS-T $(1: 1,000)$ at $4^{\circ} \mathrm{C}$ overnight. The membranes were washed with 1 x TBS-T and incubated with diluted $(1: 5,000)$ horseradish peroxidase-conjugated rabbit anti-mouse IgG (Dako, Glostrup, Denmark) for $1 \mathrm{hr}$ at room temperature. The membranes were washed with TBS-T and chemiluminescence was detected with ECL Prime Western Blotting Detection System (GE Healthcare, Parsippany, NJ, U.S.A.) using the FUSION SOLO S imaging system (Vilber-Loumat, Collegien, France).

\section{Expression of recombinant canine SIRT1}

Canine SIRT1 expression plasmid was constructed to examine canine SIRT1 protein could be detected by flow cytometry using the monoclonal antibody 1F3 against human SIRT1. We detected three canine SIRT1 mRNA transcript variants Variant1-3. The deduced amino acid sequence of Variant 2 and Variant 3 was the same. Thus we planned to express the protein coded by Variant 1 and Variant2 (Fig. 1). Nucleotides corresponding to Variant1 were synthesized at Fasmac, adding a Kozak sequence "ccacc" adjunct to the putative start codon. The codon was modified to optimize protein expression in human cells. DNA fragments corresponding to Variant1 and Variant2 were amplified by PCR from the synthesized gene using KOD-Plus-Neo polymerase (Toyobo, Osaka, Japan) and sub-cloned into pcDNA3.1 (+), a mammalian expression plasmid. The Canine SIRT1 expression plasmids, named Dog_Sirt1-long pcDNA3.1, Dog_Sirt1-short pcDNA3.1 was transfected into 293T cells [9] using X-tremeGENE HP DNA Transfection Reagent (Roche Diagnotics, Basel, Switzerland) and cultured for $48 \mathrm{hr}$. Then, the culture medium was removed and the cells were detached using TrypeLE express (Thermo Fisher Scientific). The washed cells were applied for flow cytometry analysis.

\section{Flow cytometry analysis of canine SIRT1 protein}

Canine SIRT1 expression was examined in SIRT1 expression plasmids transfected 293T cells and PBMCs. PBMCs were isolated by gradient centrifugation from heparinized blood samples using Lympholyte-H as mentioned above. PBMCs were collected and washed with PBS. PBMCs and the transfected 293 T cells were fixed and permeabilized using FIX \& PERM ${ }^{\circ}$ 
Cell Permeablization Reagents (Thermo Fisher Scientific) according to the manufacturer's instructions. The cells were incubated with 1F3 monoclonal antibody (1:200), anti- $\beta$-actin monoclonal antibody (8224, Abcam; 1:200) as a positive control, or mouse IgG1k isotype Ctrl (MOPC-21, BioLegend, CA, U.S.A.; 1:100) at $4^{\circ} \mathrm{C}$ for $30 \mathrm{~min}$. The cells were washed and incubated with phycoerythrin conjugated goat anti-mouse $\operatorname{IgG}(1: 1,000)$ for $20 \mathrm{~min}$ at room temperature. The cells were then washed with PBS and flow cytometry analysis was performed using FACSCalibur with CellQuest pro software (Becton Dickinson, Franklin Lakes, NJ, U.S.A.). SIRT1 expression in lymphocytes was represented with the ratio of SIRT1 to $\beta$-actin mean fluorescence intensity.

\section{Statistics}

The relation between SIRT1 expression (SIRT1/ $\beta$-actin ratio) and age, gender, degree of obesity was evaluated statistically. Pearson's correlation coefficient was calculated between SIRT1 and age. Differences of SIRT1 expression among gender was statistically tested by one way analysis of variance with post-hoc Tukey honestly significant difference test. Spearman's rank correlation coefficient was calculated between SIRT1 and body condition score. Significant level less than 0.05 was considered statistically significant.

\section{RESULTS}

\section{Nucleotide sequence of canine SIRT1 $m R N A$}

In our preliminary experiment, we failed to amplify the cDNA fragment containing the entire coding region of the predicted canine SIRT1 mRNA (XM_546130.4). Thus, we amplified a 5'-end- and a 3'-end cDNA fragment that covers the entire coding region. Though the 3'-end cDNA fragment was successfully amplified, the 5'-end DNA fragment was amplified only in one of five blood samples examined. A schematic view of these DNA fragments is shown in Fig. 1. The amplified 5'-end fragment included the putative initiation codon of the predicted canine SIRT1 mRNA, but nucleotides 108 to 434 of the predicted sequence were not present (named Variant 1, INSD accession No. LC342295). This deleted region is within exon 1 and does not cause a codon frame shift downstream of the transcript. Because this transcript was amplified only in one sample, $5^{\prime}$ inverse RT-PCR was conducted to detect other transcript variants. Two DNA fragments were amplified: one variant starts at nucleotide 456 (named Variant 2, INSD accession No. LC342296) of the predicted canine SIRT1 mRNA (XM_546130.4), and the other starts at nucleotide 626 (named Variant 3, INSD accession No. LC342297; Fig. 1). The putative translation start codon was predicted using the ATGpr program (http://atgpr.dbcls.jp/), indicating that the translation start at nucleotide 663 and the frame was the same as that of the predicted canine SIRT1 mRNA (XM_546130.4).

\section{Detection of canine SIRT1 protein by Western blotting}

Monoclonal antibodies against canine SIRT1 protein have not been reported. Based on the canine SIRT1 nucleotide sequence, we selected the monoclonal antibody 1F3 (Cell Signaling Technology), which was produced using the C-terminal region of human SIRT1 as the immunogen. The deduced canine SIRT amino acid sequence (Variant 1) is identical to human SIRT1 in 189 out of 190 amino acids in this region. The deduced molecular size of human SIRT1 is $81.6 \mathrm{kDa}$. A single band of approximately 128 kDa was detected in HEK293 cells, which are human-derived, by western blotting (Fig. 2). The deduced molecular size of canine SIRT1 was $70.9 \mathrm{kDa}$ for Variant 1 , and $62.1 \mathrm{kDa}$ for Variants 2 and 3. In MDCK cells, which are dog-derived, and in canine PBMC, a single band of approximately 120 $\mathrm{kDa}$ was detected in each cell line (Fig. 2).

\section{Flow cytometry analysis of canine SIRT1 in PBMCs}

To confirm the reactivity of $1 \mathrm{~F} 3$ antibody with canine SIRT1 protein, the SIRT1 expression plasmids (Dog_Sirt1long pcDNA3.1 and Dog_Sirt1-short pcDNA3.1) was transfected into 293T cells. Canine SIRT1 expression was examined by flow cytometry after fixation and permeabilization. Though this antibody may react with endogenous human SIRT1, the fluorescence intensity increased in cells transfected with the SIRT1 expression plasmids, compared with the mock-transfected cells (Fig. 3) indicating that $1 \mathrm{~F} 3$ reacted to canine SIRT1. Next, canine SIRT1 in PBMCs was examined by flow cytometry. PBMCs were fixed and permeabilized, and then incubated with 1F3 as the primary antibody. SIRT1 expression in representative samples is shown in Fig. 4. SIRT1 was detected in lymphocytes, monocytes and contaminated granulocytes. Though SIRT1 was detected in all the dogs tested, the fluorescence intensity varied among individuals (Fig. 5).

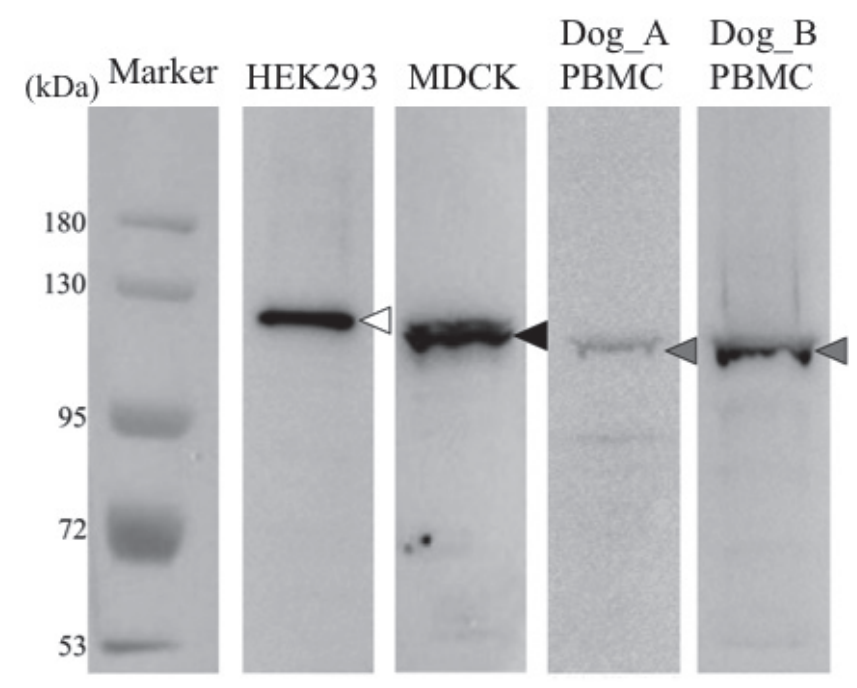

Fig. 2. Western blot analysis of canine SIRT1. Mouse anti-human SIRT1 monoclonal antibody (1F3) was used as the primary antibody. SIRT1 was detected at $128 \mathrm{kDa}$ in human HEK293 cells (white arrowhead), at $120 \mathrm{kDa}$ in canine MDCK cells (black arrowhead), and at $117 \mathrm{kDa}$ in peripheral blood mononuclear cells from two dogs (gray arrowheads). 
A

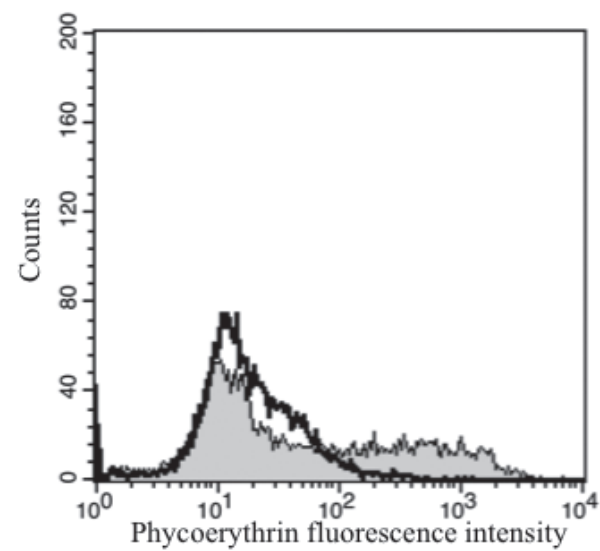

B

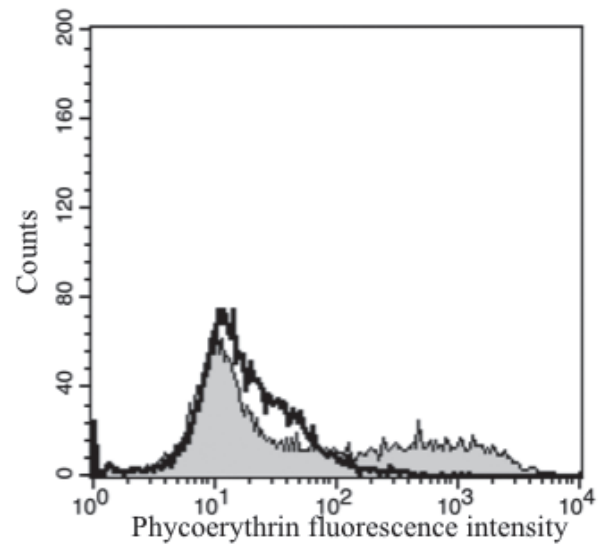

Fig. 3. Flow cytometry analysis of $293 \mathrm{~T}$ cells transfected with the dog SIRT1 expression plasmids. Intracellular SIRT1 was detected by $1 F 3$ anti-human SIRT1 antibody. A: Histogram of long SIRT1 variant (Variant1) encoding plasmid (Dog_Sirt1-long-pcDNA3.1) transfected cells (gray filled area) and mock-transfected cells (black line). B: Histogram of short SIRT1 variant (Variant2) encoding plasmid (Dog_Sirt1-shortpcDNA3.1) transfected cells (gray filled area) and mock-transfected cells (black line).

Relation of SIRT1 expression and age, gender, degree of obesity (body condition score) was examined. Correlation between SIRT1 expression and age or body condition score was not statistically significant. SIRT1 expression was statistically different among genders (Fig. 6). SIRT1 expression in neutered female dogs was higher than that in intact- female and intact-male dogs $(P<0.05)$.

\section{DISCUSSION}

In our knowledge, this is the first report that demonstrates SIRT1 transcription variants in dogs. In this study, three $5^{\prime}$ transcription variants were detected in PBMC from dogs. At least six variants have been reported in both human and mouse (The AceView genes, NCBI). Most variants in human are shorter with a deletion at exon 1 or exon 2. Though we did not examine the function of the three transcript variants in dogs, some studies have demonstrated that the SIRT1 transcript variants function differently from the full-length SIRT1, especially at the interaction point with p53 [27, 45]. We detected three variants by an RTPCR-based method and only one band of approximately $120 \mathrm{kDa}$ was observed by western blotting. The deduced molecular size of the canine SIRT1 protein was $70.9 \mathrm{kDa}$ (Variant 1) and $62.1 \mathrm{kDa}$ (Variants 2 and 3). The deduced molecular size of human SIRT1 was $81.6 \mathrm{kDa}$. We detected a $128-\mathrm{kDa}$ band using HEK293 cells, as shown in a previous study using muscle samples [7] and in the 1F3 antibody product data sheet supplied by the manufacturer (CST). The differences in observed SIRT1 molecular sizes are likely due to posttranslational glycosylation. The bands detected by western blotting in canine PBMCs presumably derived from Variants 2 and 3 mainly because only these variants were detected by inverse RT-PCR. However, the molecular size of SIRT1 derived from each transcript variants should be clarified by the expression of recombinant SIRT1 in canine cells.

To confirm the specificity of 1F3 antibody to canine SIRT1 protein, recombinant canine SIRT1 was expressed in $293 \mathrm{~T}$ cells. Because this cell line is derived from human, 1F3 also reacted with the endogenous human SIRT1. However, a marked enhancement of the signal was demonstrated in the canine SIRT1 expression plasmid-transfected cells. These results indicated that intracellular canine SIRT1 is detectable by flow cytometry using 1F3 antibody. Recently, compounds that activate SIRT1 enzymatic activity have been intensely investigated in association with lifespan extension. Recombinant canine SIRT1 protein expressed in transfected cells may be useful for screening compounds by measuring the enzymatic activity of canine SIRT1 in cultured cell lines.

Compounds that possibly enhance SIRT1 expression have also been investigated intensively [6, 7, 14, 39, 41]. Though it has not been fully demonstrated that enhancement of SIRT1 expression is associated with lifespan extension, if it comes to that, measurement of SIRT1 expression level may be valuable for monitoring the patient's condition and for evaluating the effect of interventions. In this study, we examined intracellular SIRT1 level in peripheral blood lymphocytes for ease of access in clinical cases. Though some studies measured the serum SIRT1 concentration to evaluate the SIRT1 expression level [10, 24, 29, 32, 52], the significance of the plasma SIRT1 concentration remains to be clarified because SIRT1 localizes mainly in the nucleus or the cytoplasm. SIRT1 in the cellular lysate and in the serum can potentially be measured by enzyme linked immunosorbent assay (ELISA) in dogs. However, as only one antibody is available at present, it may be difficult to establish sensitive and specific Sandwich ELISA to measure canine SIRT1. The information on the canine SIRT1 5'-end transcript variants obtained in this study will be useful for the development of antibodies and ELISA for canine SIRT1 measurement.

Minimally invasive procedures for sample collection make it easier to monitor the fluctuation of SIRT1 expression. Flow cytometry analysis can evaluate SIRT1 expression levels in individual cells, thus enabling comparison of the expression between leukocyte subsets. In this study, flow cytometry analysis was conducted using a blood sample residues (usually less than 1 


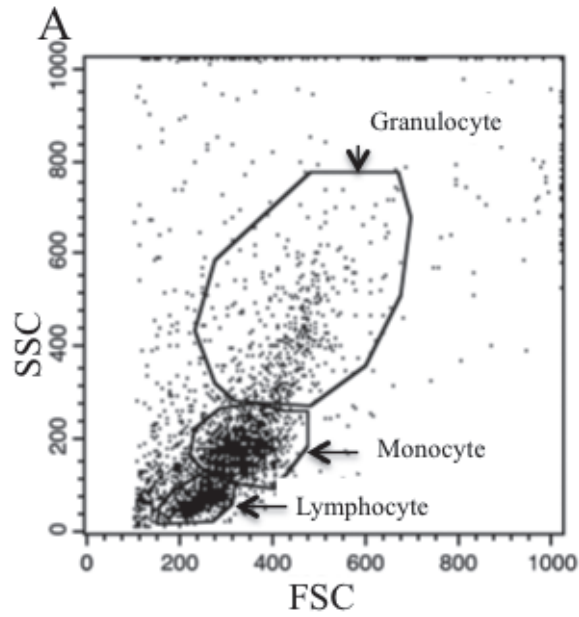

$\mathrm{C}$

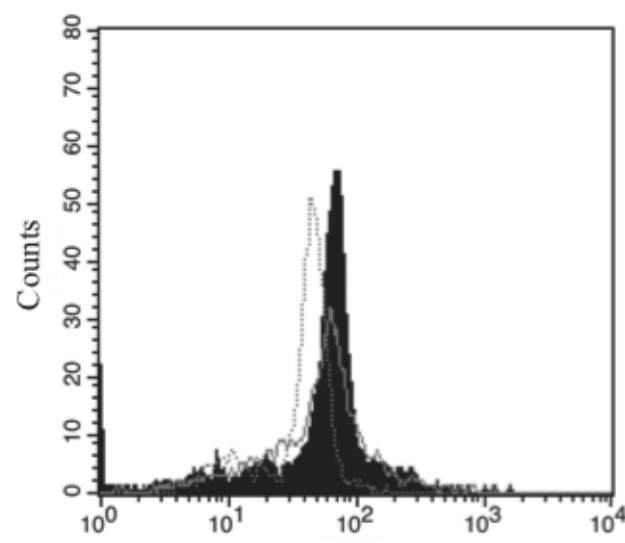

Phycoerythrin fluorescence intensity

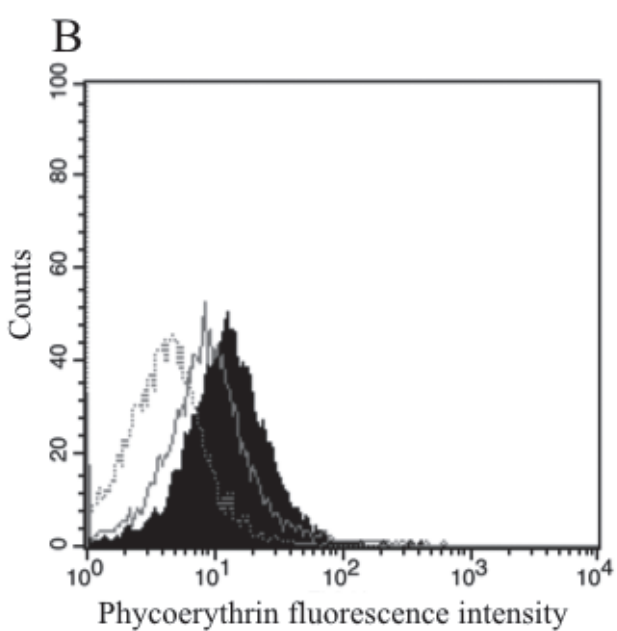

$\mathrm{D}$

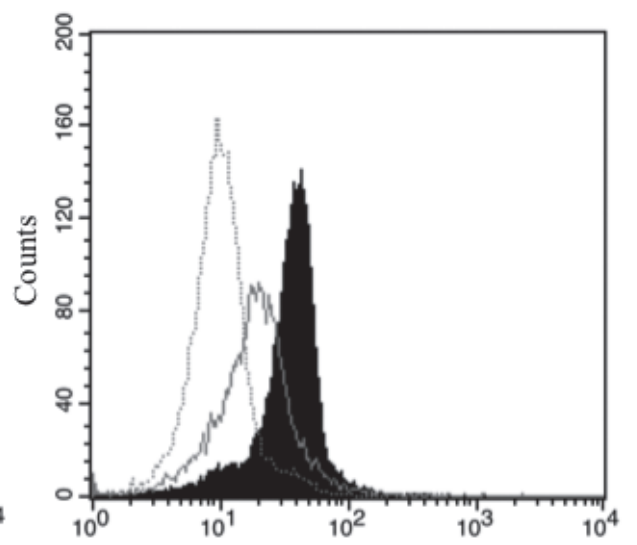

Phycoerythrin fluorescence intensity

Fig. 4. Flow cytometry analysis of SIRT1 expression in canine PBMC. Permeabilized PBMCs were reacted with 1F3 anti-human SIRT1 antibody. A: Forward scatter and side scatter dot plot analysis of a sample. The lymphocyte, monocyte and contaminated granulocyte regions are indicated by polygons. The histogram of the fluorescence intensity of the lymphocyte region (B), the monocyte region (C) and the granulocyte region (D). The histograms of samples incubated with anti-SIRT1 antibody (filled area), anti- $\beta$-actin antibody (gray line), and isotype control (dashed line) are shown in each panel.
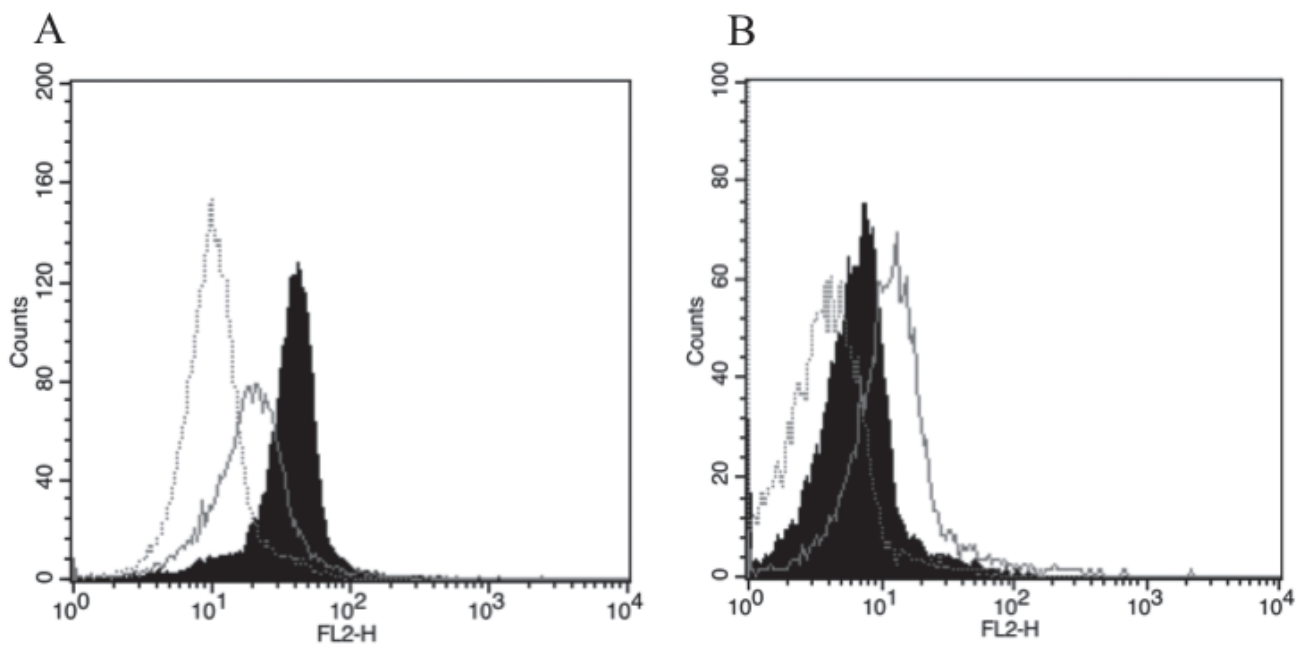

Fig. 5. SIRT1 expression in peripheral blood lymphocytes from representative cases. PBMCs were collected and permeabilized for intracellular SIRT1 staining with 1F3 anti-human SIRT1 antibody. A: Blood sample from a 4-year-old clinically healthy Border Collie. B: Blood sample from a 9-year-old Chihuahua receiving long-term glucocorticoid medication to relieve the clinical signs of a brain tumor. The fluorescent intensity histograms with anti-SIRT1 antibody (filled area), anti- $\beta$-actin antibody (gray line), and isotype control (dashed line) are shown in each panel. 

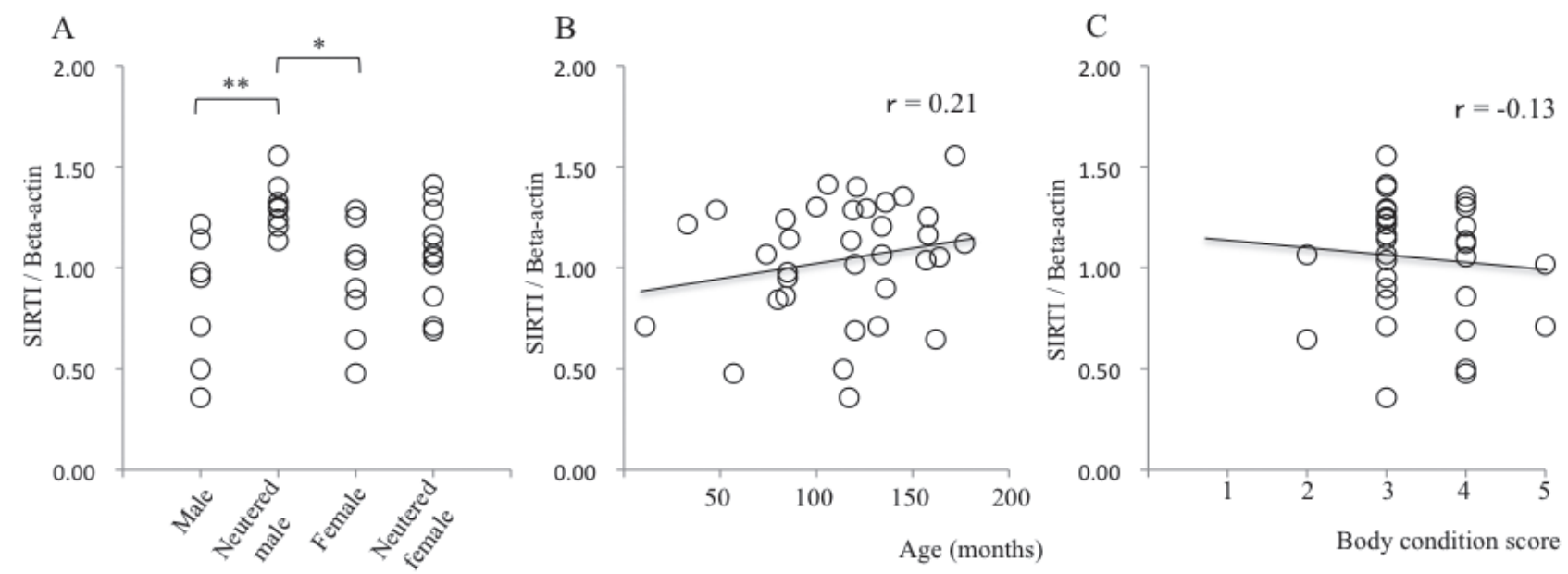

Fig. 6. Flow cytometry analysis of SIRT1 expression in peripheral blood lymphocytes from client-owned dogs ( $\mathrm{n}=34)$. SIRT1 expression was represented as SIRT1/ $\beta$-actin mean fluorescence ratio. A: Comparison of SIRT1 expression in each gender group. Significant differences between each gender group are marked with an asterisk $(P<0.05)$ or two asterisks $(P<0.01)$. B: Scatter diagram of SIRT1 expression and age with a regression line $(\mathrm{r}=0.21, P=0.24)$. C: Comparison of SIRT1 expression in each body condition score group with a regression line $(\mathrm{r}=-0.13, P=0.49)$.

$\mathrm{m} l$ of blood) obtained from animals in veterinary care. SIRT1 seemed to be expressed in all leukocyte subsets: lymphocytes, monocytes, and contaminated granulocytes. In human diabetes patients, SIRT1 was detected in monocytes and granulocytes, but not in lymphocytes, by immunocytochemical staining [52]. The discrepancy may be because of species differences or the high sensitivity of flow cytometry applied in this study. Because the permeability of the cells may differ between the samples, we used $\beta$-actin as an internal control for evaluating SIRT1 protein expression. The compensated SIRT1 expression level markedly varied among individual dogs. Though major factors that influence the SIRT1 expression were not fully clarified in this study, the level in neutered female dogs was higher than intact-female and intact-male dogs. Variance of SIRT1 protein expression by age and gender has also been reported in human [22, 25, 34]. But the trend of the variance in human was study dependent probably reflecting the difference of sample tissue and method applied. While negative correlation between SIRT1 expression and obesity has also been demonstrated in human $[19,31,33,48]$, significant correlation between SIRT1 expression and body condition score of the dogs was not found in this study. Because the samples were obtained from dogs admitted for veterinary care, other factors including disease, medication, as well as circadian change might influence the SIRT1 expression [1]. Comparison of SIRT1 expression among species or individuals in specific condition may contribute to further understanding the regulation of SIRT1 expression. Transcription factors including $\mathrm{HIC} 1, \mathrm{E} 2 \mathrm{~F} 1$ and FOXO are involved in the regulation in response to environmental change in humans $[5,40,46]$. Most of the responsive elements to these factors are located within $1 \mathrm{~kb}$ upstream from SIRT1 initiation codon. Though the promoter/enhancer region of the canine SIRTI gene has not been completely analyzed, nucleotide sequence of the region is well conserved between two species. Future studies using a large number of samples in specific condition may clarify major contributing factors that influence SIRT1 expression in dogs.

In conclusion, herein we report the nucleotide sequence of canine SIRT1 cDNA and the SIRT1 transcript variants in PBMCs. Canine SIRT1 were detectable using a monoclonal antibody developed for human SIRT1. SIRT1 expression in peripheral leukocytes can be examined by flow cytometry using this antibody. This method is applicable for further research evaluating the effect of intervention on potentially fluctuating SIRT1 expression in dogs.

ACKNOWLEDGMENT. This work was supported in part by the Japanese Society of Veterinary Clinical Nutrition, Scholarship program.

\section{REFERENCES}

1. Asher, G., Gatfield, D., Stratmann, M., Reinke, H., Dibner, C., Kreppel, F., Mostoslavsky, R., Alt, F. W. and Schibler, U. 2008. SIRT1 regulates circadian clock gene expression through PER2 deacetylation. Cell 134: 317-328. [Medline] [CrossRef]

2. Barger, J. L., Kayo, T., Vann, J. M., Arias, E. B., Wang, J., Hacker, T. A., Wang, Y., Raederstorff, D., Morrow, J. D., Leeuwenburgh, C., Allison, D. B., Saupe, K. W., Cartee, G. D., Weindruch, R. and Prolla, T. A. 2008. A low dose of dietary resveratrol partially mimics caloric restriction and retards aging parameters in mice. PLoS One 3: e2264. [Medline] [CrossRef]

3. Chang, H. C. and Guarente, L. 2013. SIRT1 mediates central circadian control in the SCN by a mechanism that decays with aging. Cell 153: 1448-1460. [Medline] [CrossRef]

4. Chen, D., Steele, A. D., Lindquist, S. and Guarente, L. 2005. Increase in activity during calorie restriction requires Sirt1. Science 310: 1641. [Medline] [CrossRef]

5. Chen, W. Y., Wang, D. H., Yen, R. C., Luo, J., Gu, W. and Baylin, S. B. 2005. Tumor suppressor HIC1 directly regulates SIRT1 to modulate p53- 
dependent DNA-damage responses. Cell 123: 437-448. [Medline] [CrossRef]

6. Chen, Y. R., Fang, S. R., Fu, Y. C., Zhou, X. H., Xu, M. Y. and Xu, W. C. 2010. Calorie restriction on insulin resistance and expression of SIRT1 and SIRT4 in rats. Biochem. Cell Biol. 88: 715-722. [Medline] [CrossRef]

7. Cohen, H. Y., Miller, C., Bitterman, K. J., Wall, N. R., Hekking, B., Kessler, B., Howitz, K. T., Gorospe, M., de Cabo, R. and Sinclair, D. A. 2004. Calorie restriction promotes mammalian cell survival by inducing the SIRT1 deacetylase. Science 305: 390-392. [Medline] [CrossRef]

8. Colman, R. J., Anderson, R. M., Johnson, S. C., Kastman, E. K., Kosmatka, K. J., Beasley, T. M., Allison, D. B., Cruzen, C., Simmons, H. A., Kemnitz, J. W. and Weindruch, R. 2009. Caloric restriction delays disease onset and mortality in rhesus monkeys. Science 325: 201-204. [Medline] [CrossRef]

9. DuBridge, R. B., Tang, P., Hsia, H. C., Leong, P. M., Miller, J. H. and Calos, M. P. 1987. Analysis of mutation in human cells by using an EpsteinBarr virus shuttle system. Mol. Cell. Biol. 7: 379-387. [Medline] [CrossRef]

10. Engin-Ustun, Y., Caglayan, E. K., Kara, M., Gocmen, A. Y., Polat, M. F. and Aktulay, A. 2016. The effect of Ramadan fasting on sirtuin and visfatin levels. Interv. Med. Appl. Sci. 8: 14-19. [Medline]

11. Grabowska, W., Sikora, E. and Bielak-Zmijewska, A. 2017. Sirtuins, a promising target in slowing down the ageing process. Biogerontology 18: 447-476. [Medline] [CrossRef]

12. Graham, F. L., Smiley, J., Russell, W. C. and Nairn, R. 1977. Characteristics of a human cell line transformed by DNA from human adenovirus type 5. J. Gen. Virol. 36: 59-74. [Medline] [CrossRef]

13. Haigis, M. C. and Sinclair, D. A. 2010. Mammalian sirtuins: biological insights and disease relevance. Annu. Rev. Pathol. 5: 253-295. [Medline] [CrossRef]

14. Hubbard, B. P. and Sinclair, D. A. 2014. Small molecule SIRT1 activators for the treatment of aging and age-related diseases. Trends Pharmacol. Sci. 35: 146-154. [Medline] [CrossRef]

15. Imai, S., Armstrong, C. M., Kaeberlein, M. and Guarente, L. 2000. Transcriptional silencing and longevity protein Sir2 is an NAD-dependent histone deacetylase. Nature 403: 795-800. [Medline] [CrossRef]

16. Imai, S. and Guarente, L. 2010. Ten years of NAD-dependent SIR2 family deacetylases: implications for metabolic diseases. Trends Pharmacol. Sci. 31: 212-220. [Medline] [CrossRef]

17. Ishikawa, S., Li, G., Takemitsu, H., Fujiwara, M., Mori, N., Yamamoto, I. and Arai, T. 2013. Change in mRNA expression of sirtuin 1 and sirtuin 3 in cats fed on high fat diet. BMC Vet. Res. 9: 187. [Medline] [CrossRef]

18. Ishikawa, S., Takemitsu, H., Habara, M., Mori, N., Yamamoto, I. and Arai, T. 2016. Sirtuin 1 suppresses nuclear factor $\kappa B$ induced transactivation and pro-inflammatory cytokine expression in cat fibroblast cells. J. Vet. Med. Sci. 77: 1681-1684. [Medline] [CrossRef]

19. Jukarainen, S., Heinonen, S., Rämö, J. T., Rinnankoski-Tuikka, R., Rappou, E., Tummers, M., Muniandy, M., Hakkarainen, A., Lundbom, J., Lundbom, N., Kaprio, J., Rissanen, A., Pirinen, E. and Pietiläinen, K. H. 2016. Obesity is associated with low NAD(+)/SIRT pathway expression in adipose tissue of BMI-discordant monozygotic twins. J. Clin. Endocrinol. Metab. 101: 275-283. [Medline] [CrossRef]

20. Kaeberlein, M., McVey, M. and Guarente, L. 1999. The SIR2/3/4 complex and SIR2 alone promote longevity in Saccharomyces cerevisiae by two different mechanisms. Genes Dev. 13: 2570-2580. [Medline] [CrossRef]

21. Kanfi, Y., Peshti, V., Gozlan, Y. M., Rathaus, M., Gil, R. and Cohen, H. Y. 2008. Regulation of SIRT1 protein levels by nutrient availability. FEBS Lett. 582: 2417-2423. [Medline] [CrossRef]

22. Kilic, U., Gok, O., Erenberk, U., Dundaroz, M. R., Torun, E., Kucukardali, Y., Elibol-Can, B., Uysal, O. and Dundar, T. 2015. A remarkable age-related increase in SIRT1 protein expression against oxidative stress in elderly: SIRT1 gene variants and longevity in human. PLoS One 10: e0117954. [Medline] [CrossRef]

23. Kendrick, A. A., Choudhury, M., Rahman, S. M., McCurdy, C. E., Friederich, M., Van Hove, J. L., Watson, P. A., Birdsey, N., Bao, J., Gius, D., Sack, M. N., Jing, E., Kahn, C. R., Friedman, J. E. and Jonscher, K. R. 2011. Fatty liver is associated with reduced SIRT3 activity and mitochondrial protein hyperacetylation. Biochem. J. 433: 505-514. [Medline] [CrossRef]

24. Lee, H., Chu, S. H., Park, J. Y., Park, H. K., Im, J. A. and Lee, J. W. 2013. Visceral adiposity is associated with SIRT1 expression in peripheral blood mononuclear cells: a pilot study. Endocr. J. 60: 1269-1273. [Medline] [CrossRef]

25. Lee, H. J. and Yang, S. J. 2017. Aging-Related Correlation between Serum Sirtuin 1 Activities and Basal Metabolic Rate in Women, but not in Men. Clin. Nutr. Res. 6: 18-26. [Medline] [CrossRef]

26. Lin, S. J., Defossez, P. A. and Guarente, L. 2000. Requirement of NAD and SIR2 for life-span extension by calorie restriction in Saccharomyces cerevisiae. Science 289: 2126-2128. [Medline] [CrossRef]

27. Lynch, C. J., Shah, Z. H., Allison, S. J., Ahmed, S. U., Ford, J., Warnock, L. J., Li, H., Serrano, M. and Milner, J. 2010. SIRT1 undergoes alternative splicing in a novel auto-regulatory loop with p53. PLoS One 5: e13502. [Medline] [CrossRef]

28. Madin, S. H. and Darby, N. B. Jr. 1958. Established kidney cell lines of normal adult bovine and ovine origin. Proc. Soc. Exp. Biol. Med. 98: 574-576. [Medline] [CrossRef]

29. Mansur, A. P., Roggerio, A., Goes, M. F. S., Avakian, S. D., Leal, D. P., Maranhão, R. C. and Strunz, C. M. C. 2017. Serum concentrations and gene expression of sirtuin 1 in healthy and slightly overweight subjects after caloric restriction or resveratrol supplementation: A randomized trial. Int. J. Cardiol. 227: 788-794. [Medline] [CrossRef]

30. Marfè, G., Tafani, M., Fiorito, F., Pagnini, U., Iovane, G. and De Martino, L. 2011. Involvement of FOXO transcription factors, TRAIL-FasL/Fas, and sirtuin proteins family in canine coronavirus type II-induced apoptosis. PLoS One 6: e27313. [Medline] [CrossRef]

31. Marfè, G., De Martino, L., Tafani, M., Irno-Consalvo, M., Pasolini, M. P., Navas, L., Papparella, S., Gambacurta, A. and Paciello, O. 2012. A multicancer-like syndrome in a dog characterized by p53 and cell cycle-checkpoint kinase 2 (CHK2) mutations and sirtuin gene (SIRT1) downregulation. Res. Vet. Sci. 93: 240-245. [Medline] [CrossRef]

32. Mariani, S., Fiore, D., Basciani, S., Persichetti, A., Contini, S., Lubrano, C., Salvatori, L., Lenzi, A. and Gnessi, L. 2015. Plasma levels of SIRT1 associate with non-alcoholic fatty liver disease in obese patients. Endocrine 49: 711-716. [Medline] [CrossRef]

33. Mariani, S., Fiore, D., Persichetti, A., Basciani, S., Lubrano, C., Poggiogalle, E., Genco, A., Donini, L. M. and Gnessi, L. 2016. Circulating SIRT1 increases after intragastric balloon fat loss in obese patients. Obes. Surg. 26: 1215-1220. [Medline] [CrossRef]

34. Massudi, H., Grant, R., Braidy, N., Guest, J., Farnsworth, B. and Guillemin, G. J. 2012. Age-associated changes in oxidative stress and NAD+ metabolism in human tissue. PLoS One 7: e42357. [Medline] [CrossRef]

35. Mattagajasingh, I., Kim, C. S., Naqvi, A., Yamamori, T., Hoffman, T. A., Jung, S. B., DeRicco, J., Kasuno, K. and Irani, K. 2007. SIRT1 promotes endothelium-dependent vascular relaxation by activating endothelial nitric oxide synthase. Proc. Natl. Acad. Sci. U.S.A. 104: 14855-14860. [Medline] [CrossRef]

36. Mendham, A. E., Duffield, R., Coutts, A. J., Marino, F., Boyko, A. and Bishop, D. J. 2015. Rugby-specific small-sided games training is an effective alternative to stationary cycling at reducing clinical risk factors associated with the development of type 2 diabetes: a randomized, controlled trial. 
PLoS One 10: e0127548. [Medline] [CrossRef]

37. Morris, B. J. 2013. Seven sirtuins for seven deadly diseases of aging. Free Radic. Biol. Med. 56: 133-171. [Medline] [CrossRef]

38. Moschen, A. R., Wieser, V., Gerner, R. R., Bichler, A., Enrich, B., Moser, P., Ebenbichler, C. F., Kaser, S. and Tilg, H. 2013. Adipose tissue and liver expression of SIRT1, 3, and 6 increase after extensive weight loss in morbid obesity. J. Hepatol. 59: 1315-1322. [Medline] [CrossRef]

39. Nisoli, E., Tonello, C., Cardile, A., Cozzi, V., Bracale, R., Tedesco, L., Falcone, S., Valerio, A., Cantoni, O., Clementi, E., Moncada, S. and Carruba, M. O. 2005. Calorie restriction promotes mitochondrial biogenesis by inducing the expression of eNOS. Science 310: 314-317. [Medline] [CrossRef]

40. Pediconi, N., Guerrieri, F., Vossio, S., Bruno, T., Belloni, L., Schinzari, V., Scisciani, C., Fanciulli, M. and Levrero, M. 2009. hSirT1-dependent regulation of the PCAF-E2F1-p73 apoptotic pathway in response to DNA damage. Mol. Cell. Biol. 29: 1989-1998. [Medline] [CrossRef]

41. Rasbach, K. A. and Schnellmann, R. G. 2008. Isoflavones promote mitochondrial biogenesis. J. Pharmacol. Exp. Ther. 325: 536-543. [Medline] [CrossRef]

42. Rehan, L., Laszki-Szcząchor, K., Sobieszczańska, M. and Polak-Jonkisz, D. 2014. SIRT1 and NAD as regulators of ageing. Life Sci. 105: 1-6. [Medline] [CrossRef]

43. Rogina, B. and Helfand, S. L. 2004. Sir2 mediates longevity in the fly through a pathway related to calorie restriction. Proc. Natl. Acad. Sci. U.S.A. 101: 15998-16003. [Medline] [CrossRef]

44. Satoh, A., Brace, C. S., Rensing, N., Cliften, P., Wozniak, D. F., Herzog, E. D., Yamada, K. A. and Imai, S. 2013. Sirt1 extends life span and delays aging in mice through the regulation of Nk2 homeobox 1 in the DMH and LH. Cell Metab. 18: 416-430. [Medline] [CrossRef]

45. Shah, Z. H., Ahmed, S. U., Ford, J. R., Allison, S. J., Knight, J. R. and Milner, J. 2012. A deacetylase-deficient SIRT1 variant opposes full-length SIRT1 in regulating tumor suppressor p53 and governs expression of cancer-related genes. Mol. Cell. Biol. 32: 704-716. [Medline] [CrossRef]

46. Xiong, S., Salazar, G., Patrushev, N. and Alexander, R. W. 2011. FoxO1 mediates an autofeedback loop regulating SIRT1 expression. J. Biol. Chem. 286: 5289-5299. [Medline] [CrossRef]

47. Song, R., Xu, W., Chen, Y., Li, Z., Zeng, Y. and Fu, Y. 2011. The expression of Sirtuins 1 and 4 in peripheral blood leukocytes from patients with type 2 diabetes. Eur. J. Histochem. 55: e10. [Medline] [CrossRef]

48. Stefanowicz, M., Nikołajuk, A., Matulewicz, N. and Karczewska-Kupczewska, M. 2018. Adipose tissue, but not skeletal muscle, sirtuin 1 expression is decreased in obesity and related to insulin sensitivity. Endocrine 60: 263-271. [Medline] [CrossRef]

49. Tao, R., Wei, D., Gao, H., Liu, Y., DePinho, R. A. and Dong, X. C. 2011. Hepatic FoxOs regulate lipid metabolism via modulation of expression of the nicotinamide phosphoribosyltransferase gene. J. Biol. Chem. 286: 14681-14690. [Medline] [CrossRef]

50. Tissenbaum, H. A. and Guarente, L. 2001. Increased dosage of a sir-2 gene extends lifespan in Caenorhabditis elegans. Nature 410: $227-230$. [Medline] [CrossRef]

51. Vaziri, H., Dessain, S. K., Ng Eaton, E., Imai, S. I., Frye, R. A., Pandita, T. K., Guarente, L. and Weinberg, R. A. 2001. hSIR2(SIRT1) functions as an NAD-dependent p53 deacetylase. Cell 107: 149-159. [Medline] [CrossRef]

52. Wang, Y., Li, D., Ma, G., Li, W., Wu, J., Lai, T., Huang, D., Zhao, X., Lv, Q., Chen, M. and Wu, B. 2015. Increases in peripheral SIRT1: a new biological characteristic of asthma. Respirology 20: 1066-1072. [Medline] [CrossRef]

53. Wierman, M. B. and Smith, J. S. 2014. Yeast sirtuins and the regulation of aging. FEMS Yeast Res. 14: 73-88. [Medline] [CrossRef] 